\title{
Obstetric analgesia in labor and its association with neonatal outcomes
}

\author{
Analgesia obstétrica no trabalho de parto e sua associação com desfechos neonatais \\ Analgesia obstétrica en el trabajo de parto y su asociación con resultados neonatales
}

Yasmin Aparecida Pires Silva' ORCID: 0000-0002-0608-4917

Fernanda Gontijo Araújo' ORCID: 0000-0003-3528-2493

Torcata Amorim' ORCID: 0000-0002-9177-9958

Eunice Francisca Martins' ORCID: 0000-0002-2014-8470

Mariana Santos Felisbino-Mendes' ORCID: 0000-0001-5321-5708

'Universidade Federal de Minas Gerais. Belo Horizonte, Minas Gerais, Brazil.

How to cite this article: Silva YAP, Araújo FG, Amorim T, Martins EF, Felisbino-Mendes MS. Obstetric analgesia in labor and its association with neonatal outcomes. Rev Bras Enferm. 2020;73(5):e 20180757. doi: http://dx.doi.org/10.1590/0034-7167-2018-0757

Corresponding author: Mariana Santos Felisbino-Mendes marianafelisbino@yahoo.com.br

EDITOR IN CHIEF: Dulce Aparecida Barbosa ASSOCIATE EDITOR: Andrea Bernardes

Submission: 09-21-2018 Approval: 07-03-2019

\section{ABSTRACT}

Objetive: To investigate the association between analgesia during labor and occurrence of neonatal outcomes. Method: Retrospective cohort study with medical records of 850 parturient. The exposure variable of interest was receiving pharmacological analgesia during labor and neonatal outcomes were: one- and five-minute Apgar, resuscitation maneuvers and referral of the newborn to Neonatal ICU. A logistic regression was carried out to obtain Odds Ratios and $95 \%$ confidence interval, with adjustment for confounding factors. Results: Among the women studied, $35 \%$ received analgesia and this use was associated with a greater chance of neonatal outcomes such as one-minute Apgar $<7(p<0.0001)$, resuscitation maneuvers ( $p$ $<0.001)$ and referral to the Neonatal ICU ( $p=0.004)$, mostly were among low-risk pregnant women, even after adjustments. Conclusion: The use of pharmacological analgesia during labor is associated with one-minute Apgar $<7$, resuscitation maneuvers and referral to the Neonatal ICU.

Descriptors: Analgesia, Obstetrical; Infant, Neonatal; Labor, Obstetric; Apgar Score; Intensive Care Units, Neonatal.

\section{RESUMO}

Objetivo: Investigar a associação entre analgesia no trabalho de parto e ocorrência de desfechos neonatais. Método: Estudo de coorte retrospectiva com dados de prontuários de 850 parturientes. A exposição foi receber analgesia farmacológica no trabalho de parto e os desfechos: Apgar do primeiro e quinto minuto $<7$, manobras de reanimação e encaminhamento para Unidade de Terapia Intensiva Neonatal (UTI). Utilizou-se regressão logística para obter Odds Ratio (OR) e intervalo de $95 \%$ de confiança (IC95\%), sendo ajustados por confundidores. Resultados: Das mulheres estudadas, 35\% receberam analgesia e seu uso esteve associado a maior chance de desfechos, como: Apgar do primeiro minuto $<7(p<0,0001)$, manobras de reanimação $(p<0,001)$ e encaminhamento para UTI Neonatal $(p=0,004)$, principalmente entre gestantes de risco habitual, mesmo após ajustes. Conclusão: $\mathrm{O}$ uso de analgesia farmacológica durante o trabalho de parto foi associado a Apgar do primeiro minuto $<7$, manobras de reanimação $\mathrm{e}$ encaminhamento para UTI neonatal.

Descritores: Analgesia Obstétrica; Recém-Nascido; Trabalho de Parto; Índice de Apgar; Unidade de Terapia Intensiva Neonatal.

\section{RESUMEN}

Objetivo: Investigar la asociación entre la analgesia en el trabajo de parto y la aparición de resultados neonatales. Método: Estudio de cohorte retrospectivo con datos de 850 parturientas. La exposición fue recibir analgesia farmacológica en el trabajo de parto, resultados: Apgar del primer y quinto minuto $<7$, maniobras de reanimación y derivación a la UCIN. La regresión logística se utilizó para obtener el Odds Ratio (OR) y el intervalo de confianza del 95\% (IC95\%), ajustado por variables de confusión. Resultados: De las mujeres estudiadas, el $35 \%$ recibió analgesia y su uso se asoció con una mayor probabilidad de resultados como: Apgar en el primer minuto $<7(p<0,0001)$, maniobras de reanimación $(p<0,001)$ y derivación a la UCIN $(p=0,004)$. Conclusión: el uso de analgesia farmacológica durante el trabajo de parto se asoció con Apgar < 7 en el primer minuto, maniobras de reanimación y derivación a la UCIN. Descriptores: Analgesia Obstétrica; Recién nacido; Trabajo de Parto; Test de Apgar; Unidad de Cuidados Intensivos Neonatales (UCIN). 


\section{INTRODUCTION}

Advancements in obstetrics have improved the rates of maternal and perinatal morbidity and mortality. However, the model that has been consolidated treats gestation, birth and delivery as pathological events and contributes to the exposure of women and newborns to high rates of unnecessary and harmful interventions, which should be used only when indicated, and not as routine treatment. An example is the use of pharmacological analgesia, an obstetric intervention that is frequently used inappropriately for pain relief during labor ${ }^{(1)}$.

The pain of labor and its relief are important aspects for parturient, companions and newborns and are related to the evolution and outcome of delivery care. There are different pharmacological and non-pharmacological methods used to relieve pain during labor ${ }^{(2)}$. Non-pharmacological methods are strategies used during labor to increase pain tolerance and include a variety of techniques that, beyond the physical sensation of pain, also include psycho emotional and spiritual aspects of care ${ }^{(3-4)}$. Pharmacological methods are directed at eliminating the physical sensation of pain and include various substances and techniques ${ }^{(4)}$. According to national guidelines for normal delivery, non-pharmacological methods should be used before pharmacological methods and should be offered according to recommendations ${ }^{(5-6)}$.

In Brazil, the right to pain relief and management is ensured by directives of the Ministry of Health (no. 2,815, 1998 and no. $572,2000)$, which included obstetric analgesia in the obstetric procedures reimbursed by the Brazilian National Health System (SUS) and in the guidelines for the humanization of birth ${ }^{(5,7)}$. In addition, in 2011, the Rede Cegonha was created and proposed, among its objectives, a new model for labor and delivery care, centered on the role of women ${ }^{(8)}$. This model aims to offer women and children a humane and quality care, providing a gestation, labor and delivery experience with safety, dignity and beauty, emphasizing the idea that giving birth is not a disease or pathological process ${ }^{(8-9)}$, but a physiological and natural process that must be a unique experience for the woman and her partner, so it should be minimally invasive and use technology appropriately ${ }^{(8)}$. For this, good practices in labor and delivery are recommended ${ }^{(8)}$ and include pain management strategies.

In this context, obstetric analgesia has made great strides and, in recent years, more and more women have opted for using it for labor pain relief ${ }^{(10-11)}$. Among the types of analgesia, the epidural provides more effective pain relief and greater maternal satisfaction; in addition, women remain involved, preventing hyperventilation and reducing maternal stress ${ }^{(12)}$. The ideal epidural method should be the one with the least adverse effect on the fetus and the newborn ${ }^{(10)}$. However, a previous study investigated the relationship between labor analgesia and delivery outcomes and found that the use of pharmacological analgesia in labor was associated with an increased risk of instrumental vaginal delivery ${ }^{(13)}$. Other studies have also shown that the use of analgesia may be associated with neonatal outcomes ${ }^{(14-15)}$.

A recent integrative review has shown that studies on obstetric analgesia, maternal and fetal outcomes in Brazil have increased ${ }^{(10)}$. However, the association between the use of analgesia and neonatal outcomes is still controversial ${ }^{(10,14)}$. In addition, most of the studies compare different types of analgesia, and only few compare the use and non-use of analgesia. Given this scenario, it is relevant to analyze the association between pharmacological analgesia and neonatal outcomes.

\section{OBJECTIVE}

To investigate the association between pharmacological analgesia in labor and occurrence of neonatal outcomes.

\section{METHOD}

\section{Ethical aspects}

This study was approved by the Research Ethics Committee of the Federal University of Minas Gerais (CONEP/UFMG) and by the Research Ethics Committee of the maternity studied.

\section{Design, setting and period}

Retrospective cohort study based on data from the medical records of women who delivered in a reference maternity hospital in Belo Horizonte, Minas Gerais. The hospital handles more than 10,000 deliveries a year and has a multidisciplinary and interdisciplinary team focused on humane assistance, women's empowerment and on the development of the mother-child bond.

The data were collected from the medical records through a structured script containing 27 objective questions. Data collection occurred between February 2013 and May 2015.

\section{Population or sample}

Simple random sampling was used to select 978 deliveries performed in 2013 in a public maternity hospital in Belo HorizonteMG. This sample was selected by monthly random draws. Further information on the composition of the sample can be found in a previous publication ${ }^{(13)}$.

\section{Inclusion and exclusion criteria}

Inclusion criteria for the study were full-term gestations, with single live fetus in cephalic presentation. Multiple pregnancies, elective caesarean sections, prematurity, dead fetuses, abnormal presentations and intrapartum cesarean delivery were excluded. The final sample was composed of 850 women who had vaginal deliveries.

\section{Study protocol}

In this study, the exposure of interest was the use of pharmacological analgesia during labor (yes, no). The method of analgesia chosen was epidural. The outcomes analyzed were one- and five-minute Apgar (Apgar <7; Apgar $\geq 7$ ), neonatal resuscitation in the delivery room (yes, no) and referral to the Neonatal ICU (yes, no). The covariates studied were maternal age (13 to 19 years, 20 to 29 years, 31 years or more), gestational age (37 to 40 weeks, 41 weeks or more) and number of previous deliveries (none, more than one). 


\section{Analysis of results and statistics}

Means and proportions of neonatal outcomes were estimated. The Pearson's Chi-squared test, the Fisher's test and the Student's T-test were used to evaluate the statistical differences between the exposure of interest and the outcomes. The association between exposure and binary outcomes was analyzed using logistic regression, with unadjusted Odds Ratio (OR) and 95\% confidence interval $(95 \% \mathrm{Cl})$. The analysis was then adjusted for confounding factors (gestational age, maternal age and number of previous deliveries). The analysis was stratified according to gestation risk: low risk and high risk, according to the criteria of the Ministry of Health $^{(16)}$. Six women did not have their gestation risk recorded. Statistical analyzes were performed in the program Stata, version 14.0 (Stata Corp., College Station, TX, USA). children of mothers who received analgesia. The use of analgesia during labor was also associated with this outcome (OR $=3.5 ; 95 \%$ Cl: 1.91-6.33).

It was observed that $18(2.1 \%)$ neonates were referred to the neonatal ICU, and the chance of ICU referral increased with the use of analgesia. This association remained after adjusting for maternal age, gestational age and number of previous deliveries (Adjusted $\mathrm{OR}=3.85,95 \% \mathrm{Cl}:$ 1.40-10.65).

When analyzing the neonatal outcomes stratified by gestation risk, it was verified that, after adjustments, one-minute Apgar scores less than $7(\mathrm{OR}=2.73,95 \% \mathrm{Cl} 1.35-5.53)$ and referral for Neonatal ICU $(\mathrm{OR}=4.32,95 \% \mathrm{Cl} 1.27-14.66)$ remained associated with analgesia exposure only for low risk pregnant women. Regarding the need for resuscitation, the association remained independent of gestation risk, even after adjustments ( $\mathrm{OR}=3.69,95 \% \mathrm{Cl}, 1.15-11.71)$ (Table 3).

\section{RESULTS}

The study population had a mean age of 24.2 years $\pm S D( \pm 6.4)$, ranging from 13 to 45 years. The most frequent age group was 20 to 29 years (49.0\%). Most of the women were primiparous (50.7\%), had a gestational age between 37 and 40 weeks $(87.7 \%)$, had more than 05 prenatal visits (76.9\%) and were classified as low risk (73.2\%) (data not shown).

Among the women studied, 297 (35\%) received analgesia. Of these women, six did not have their gestation risk identified, 213 (71.7\%) were classified as low risk pregnant women and $78(26.3 \%)$ as high risk pregnant women.

According to the data, analgesia was more frequent among women who had a companion or doula (99\%), had between 9 and 11 years of education (59.1\%) and were between 20 and 29 years (49.7\%). It was observed that the use of analgesia was more frequent among nulliparous women $(p<0.0001)$. The mean \pm SD duration of labor was 7.1 hours for those who received analgesia and 4.4 hours for those who did not receive it $(p<0.0001)$. The women received analgesia with a mean of $7.4( \pm 1.3) \mathrm{cm}$ of cervical dilation, which ranged from 3 to $10 \mathrm{~cm}$ (Table 1).

Among the total number of newborns (NB), 47 (5.5\%) had one-minute Apgar score less than 7, and of these, 28 (9.4\%) were children of mothers who received analgesia ( $p<0.0001)$. The use of analgesia tripled the chance of newborns with a one-minute Apgar score less than 7, even after adjustment for maternal age, gestational age and number of previous deliveries (adjusted OR $=2.80,95 \% \mathrm{Cl} 1.52-5.17)$. Five-minute Apgar score was less than 7 for 8 ( $0.9 \%$ ) newborns, and there was no association between analgesia and this outcome (Table 2).

Among the newborns, 49 required neonatal resuscitations, and 31 (10.4\%) of these were
Table 1 - Characteristics of the women and of the delivery according to the use of analgesia

\begin{tabular}{|c|c|c|c|c|c|}
\hline \multirow{2}{*}{ Characteristics } & \multicolumn{4}{|c|}{ Use of analgesia } & \multirow{2}{*}{$\underset{\text { value }^{*}}{\boldsymbol{p}}$} \\
\hline & n (\%) & $\begin{array}{l}\text { Yes } \\
\text { mean } \pm(S D)\end{array}$ & n (\%) & $\begin{array}{l}\text { No } \\
\text { mean } \pm(S D)\end{array}$ & \\
\hline Companion/doula & & & & & 0.124 \\
\hline Yes & $286(99.0)$ & & $516(97.4)$ & & \\
\hline No & $3(1.0)$ & & $14(2.6)$ & & \\
\hline Level of education & & & & & 0.07 \\
\hline 0 to 8 years of education & $16(8.1)$ & & $16(4.3)$ & & \\
\hline 9 to 11 years & $117(59.1)$ & & $208(55.8)$ & & \\
\hline 12 years or more & $65(32.8)$ & & 149 (39.9) & & \\
\hline Age & & & & & 0.791 \\
\hline 13 to 19 years & $86(29.1)$ & & $155(28.0)$ & & \\
\hline 20 to 29 years & $147(49.7)$ & & $269(48.7)$ & & \\
\hline 31 years or more & $63(21.3)$ & & $129(23.3)$ & & \\
\hline Previous deliveries & & & & & $<0.0001$ \\
\hline None & $182(61.7)$ & & $246(44.8)$ & & \\
\hline More than one & $113(38.3)$ & & $303(55.2)$ & & \\
\hline Duration of labor & & $7.1( \pm 3.1)$ & & $4.3( \pm 2.7)$ & $<0.0001^{* *}$ \\
\hline Gestational age & & $39.3( \pm 1.1)$ & & $39.0( \pm 1.2)$ & 0.946 \\
\hline 37 to 40 weeks & $260(87.5)$ & & $485(87.7)$ & & \\
\hline 41 weeks or more & $37(12.5)$ & & $68(12.3)$ & & \\
\hline
\end{tabular}

Table 2 - Neonatal outcomes according to use of analgesia during labor among women who had a vaginal delivery

\begin{tabular}{|c|c|c|c|c|}
\hline \multirow[b]{2}{*}{ Neonatal outcome } & \multicolumn{4}{|c|}{ Women with vaginal delivery $(n=850)$} \\
\hline & n (\%) & $\underset{\text { value }}{p}$ & OR* $(95 \% \mathrm{CI})$ & OR* $(95 \% \mathrm{Cl})$ \\
\hline 1 min Apgar $<7$ & & $<0.0001$ & & \\
\hline With analgesia & $28(9.4)$ & & $2.92(1.60-5.32)$ & $2.80(1.52-5.17)$ \\
\hline Without analgesia & $19(3.4)$ & & Ref. & Ref. \\
\hline 5 min Apgar $<7$ & & 0.101 & & \\
\hline With analgesia & $5(1.7)$ & & $3.13(0.74-13.20)$ & . \\
\hline Without analgesia & $3(0.5)$ & & Ref. & \\
\hline CPR & & $<0.0001$ & & \\
\hline With analgesia & $31(10.5)$ & & $3.48(1.91-6.33)$ & $3.21(1.74-5.90)$ \\
\hline Without analgesia & $18(3.2)$ & & Ref. & Ref. \\
\hline NB referred to the ICU & & 0.004 & & \\
\hline With analgesia & $12(4.1)$ & & $3.89(1.44-10.48)$ & $3.85(1.40-10.65)$ \\
\hline Without analgesia & $6(1.1)$ & & Ref. & Ref. \\
\hline
\end{tabular}


Table 3 - Neonatal outcomes according to use of analgesia during labor and according to gestation risk

\begin{tabular}{|c|c|c|c|c|c|c|c|c|}
\hline \multirow{2}{*}{ Neonatal outcome } & \multicolumn{4}{|c|}{ Low risk pregnant $(n=614)$} & \multicolumn{4}{|c|}{ High risk pregnant $(n=225)$} \\
\hline & n (\%) & $p$ value & $\mathrm{OR}^{* *}(95 \% \mathrm{Cl})$ & $\mathrm{OR}^{* * *}(95 \% \mathrm{Cl})$ & n (\%) & $p$ value & $O R^{* *}(95 \% \mathrm{Cl})$ & OR*** $(95 \% \mathrm{Cl})$ \\
\hline $1 \min$ Apgar $<7$ & & $0.003^{*}$ & & & & $0.052^{*}$ & & \\
\hline With analgesia & $21(9.8)$ & & $2.80(1.41-5.56)$ & $2.73(1.35-5.53)$ & $07(8.9)$ & & $3.52(0.99-12.43)$ & - \\
\hline Without analgesia & $15(3.8)$ & & Ref. & & $04(2.7)$ & & Ref. & \\
\hline 5 min Apgar $<7$ & & $0.190^{*}$ & & & & $1.000^{*}$ & & \\
\hline With analgesia & $4(1.88)$ & & $3.80(0.69-20.96)$ & - & $1(1.28)$ & & $1.89(0.11-30.73)$ & - \\
\hline Without analgesia & $2(0.50)$ & & Ref. & & $1(0.8)$ & & Ref. & \\
\hline CPR & & $<0.0001$ & & & & 0.015 & & \\
\hline With analgesia & $22(10.3)$ & & $3.43(1.69-6.97)$ & $3.12(1.50-6.46)$ & $9(11.6)$ & & $3.68(1.16-11.71)$ & $3.69(1.15-11.71)$ \\
\hline Without analgesia & $13(3.2)$ & & Ref. & & $5(3.4)$ & & Ref. & Ref. \\
\hline NB referred to the ICU & & $0.014^{*}$ & & & & $0.342^{*}$ & & \\
\hline With analgesia & $9(4.2)$ & & $4.44(1.35-14.60)$ & $4.32(1.27-14.66)$ & $3(3.9)$ & & $2.93(0.48-17.97)$ & - \\
\hline Without analgesia & $4(1.0)$ & & Ref. & & $2(1.3)$ & & Ref. & \\
\hline
\end{tabular}

Additionally, the relationship between one-minute Apgar scores and the need for resuscitation in the delivery room $(p<0.0001)$ was analyzed, and a high correlation between these outcomes was found (76.6\%). There was also a correlation between fiveminute Apgar scores and referral to the neonatal ICU ( $p<0.0001)$, for which $100 \%$ of the NB with five-minute Apgar scores lower than 7 were referred.

\section{DISCUSSION}

The results of this study pointed to the association between pharmacological analgesia during labor and unfavorable neonatal outcomes, corroborating the findings of another retrospective study that also showed an association between analgesia and adverse effects on NBs, such as lower one-minute Apgar scores, need for resuscitation in the delivery room and referral of the newborn to the neonatal ICU ${ }^{(14)}$. It should also be noted that there was a study that did not find the same relation ${ }^{(15)}$.

Some studies have found an association between the use of analgesia and one-minute Apgar scores less than 7; the same did not occur with the five-minute Apgar scores ${ }^{(14)}$, which may be related to resuscitation maneuvers, showing that these are effective to improve the condition of the newborn, resulting in a five-minute Apgar greater than $7^{(17)}$. This was demonstrated by the high correlation between Apgar 1 minute less than 7 and resuscitation maneuvers found in this study, as well as in other studies $^{(17)}$. It is known that Apgar should not be used to indicate CPR for the newborn ${ }^{(18-19)}$, but it is considered a viable parameter to evaluate the response and effectiveness of the measures taken ${ }^{(17,19)}$. It is also worth noting that, in this study, all the NBs who had five-minute Apgar $<7$ were referred to the neonatal ICU, demonstrating the cascade effect of the outcomes analyzed.

This association is demonstrated in studies that showed the relationship between epidural analgesia, intrapartum maternal fever, and adverse neonatal outcomes ${ }^{(20-21)}$. This theory is based on intrapartum maternal hyperthermia caused by the use of epidural analgesia, both of which have been related to low Apgar scores, cardiopulmonary resuscitation and early-onset neonatal seizures. This latter outcome could have implications for longer-term health of the infant. The biological mechanism of this association is not yet clear however, it is known that fever is not due to infection and it is associated to an inflammatory response ${ }^{(20,22)}$.

Another possible explanation may be the effect of analgesia on labor length, which has been previously demonstrated ${ }^{(13,23-24)}$. It is known that nulliparous women tend to have longer labor compared to multiparous women ${ }^{(23)}$, and that the use of analgesia is associated with instrumental vaginal delivery ${ }^{(13)}$, which may be associated with neonatal outcomes such as low Apgar scores ${ }^{(23)}$.

It is known that the use of analgesia in the maternity hospital studied is not indiscriminate and that the care offered follows recommendations of good practices in labor and delivery. This can be verified in the results of this study, such as the presence of a companion or doula in the majority of deliveries ${ }^{(13)}$ and the use of more common pharmacological analgesia in primiparous women ${ }^{(13,17,23)}$ and in low-risk pregnant women, since the presence of risk factors could contraindicate the use of pharmacological

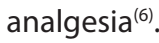

For many women, the pain of labor and delivery is the worst pain they have ever experienced ${ }^{(25)}$. It is known that this pain is the result of complex interactions of inhibitory and excitatory effects and, even though its mechanisms are similar to acute pain, there are specific neurophysiological, obstetric, psychological and sociological factor that affect its intensity ${ }^{(4)}$. Considering these aspects, strategies to reduce stress and anxiety during labor should be developed, since the use of several analgesics in itself is not able to manage the multidimensional phenomenon of labor pain ${ }^{(3)}$.

In many situations, pain can be managed with adequate physical and emotional support. Professionals must demonstrate safety to the woman in labor and guide her about the evolution of her labor, the pain and the methods of relief. The presence of a companion of the woman's choice can contribute with this support and security ${ }^{(26)}$, but this person must also be oriented and supported in order to support. In addition, non-pharmacological methods such as body massages, bathing (shower or immersion), ambulation, breathing and relaxation techniques, comforting touches and birthing balls should also be used for pain relief(26). The obstetrics nurse has the role of providing care based on support, safety and use of non-pharmacological methods of pain relief ${ }^{(1,27)}$. However, when women need or request pharmacological 
methods, they should be used ${ }^{(26)}$, but only after the consent of the woman, who must be aware of the risks, benefits and implications of this analgesia to her childbirth ${ }^{(26)}$.

Reducing the damage caused to the woman and fetus by the use of analgesia has been the objective of different studies. Recent meta-analysis results demonstrated that non-pharmacological approaches are associated with a reduction in epidural analgesia and a higher maternal satisfaction with childbirth, providing significant benefits to women and their infants without causing additional harm. In turn, pharmacological analgesia was associated with odds of cesarean delivery, instrumental delivery, use of oxytocin, longer duration of labor and a lesser satisfaction with childbirth ${ }^{(3)}$. In addition, results of a systematic review have shown that nonpharmacological methods are effective in reducing stress and relieving pain and anxiety and contribute to maternal satisfaction ${ }^{(28)}$.

Therefore, prenatal care is a favorable moment for providing guidelines that facilitate informed choices about the delivery process, especially in relation to pain control strategies, including non-pharmacological methods and analgesia, and their indication, risks and benefits. These guidelines have proven efficacy in reducing the use of epidural analgesia and improving women's satisfaction with labor ${ }^{(25)}$ and have been recommended for the practice of nurses in prenatal care, both for low-risk and high-risk pregnant women, in order to recognize risks and adopt postures that benefit the woman and the newborn ${ }^{(29)}$.

Important recommendations regarding labor analgesia should be followed, such as administration technique, dose, substances used and maintenance of analgesia during labor $^{(5)}$. In addition, the clinical evaluation for the indication or contraindication of analgesia should be undertaken and include evaluation of fetal well-being ${ }^{(30)}$. Among these contraindications, the maternal refusal should be emphasized, along with the presence of infection, hemorrhage and poor positioning of the fetus ${ }^{(30)}$. Accurate indication of the use of analgesia can reduce harm to the fetus and to the woman. Thus, providing information on the advantages and disadvantages of this procedure can contribute to the humanization of labor ${ }^{(1,5)}$.

It is important to note that in the context of the humanization and demedicalization of delivery care, nursing professionals have a fundamental role in the construction of a prosperous environment in labor and delivery care in Brazil, which should be based on public policies of humanization, use of appropriate and necessary technologies and consideration of the singularity of each woman ${ }^{(27)}$. More specifically, obstetric nursing has an important participation in labor and delivery care and important assistance contributions in this process, according to national and international guidelines for good practices and based on the principles of humanization ${ }^{(1)}$.

\section{Limitations of the study}

This study presents some limitations, such as incomplete or absent records, which made it impossible to identify other factors that could be relevant for the association of analgesia and unfavorable neonatal outcomes, such as duration of each phase of labor, doses and substances used for analgesia, and specific aspects related to the health of the newborn. Despite this, it should be noted that multiple pregnancies, elective caesarean sections, prematurity, dead fetuses and abnormal presentation were exclusion criteria of the study. In addition, the gestation risk was stratified, and the associations remained for low-risk pregnant women. It should also be noted that the results were adjusted for important confounding factors in this relation.

\section{Contributions to the areas of Nursing, health or public policies}

A care model in which health systems contribute to the empowerment of women to make decisions that benefit themselves and their child should be developed in order to achieve the best physical, emotional and psychological outcome for women and their infants. Thus, the role of nursing professionals, beginning in prenatal care and preparing the woman for the delivery process, including aspects related to labor pain and coping strategies, is highlighted. Women should be guided on non-pharmacological and pharmacological pain relief methods, highlighting the risks and benefits of each method, in addition to their rights.

\section{CONCLUSION}

The use of pharmacological analgesia during labor was associated with neonatal outcomes such as one-minute Apgar scores less than 7, resuscitation maneuvers, and referral of the newborn to the Neonatal ICU, especially for low-risk pregnant women.

\section{ACKNOWLEDGEMENTS}

The authors acknowledge the support from the Pró-Reitoria de Pesquisa, Universidade Federal de Minas Gerais (PRPq/UFMG).

\section{REFERENCES}

1. Sousa AMM, Souza KV, Rezende EM, Martins EF, Campos D, Lansky S. Practices in childbirth care in maternity with inclusion of obstetric nurses in Belo Horizonte, Minas Gerais. Esc Anna Nery. 2016;20(2):324-31. doi: 10.5935/1414-8145.20160044

2. Cunha A. Analgesia e anestesia no trabalho de parto e parto. Femina. 2010;38(11):599-606.

3. Chaillet N, Belaid L, Crochetiere C, Roy L, Gagné GP, Moutquin JM, et al. Nonpharmacologic approaches for pain management during labor compared with usual care: a meta-analysis. Birth. 2014;41(2):122-37. doi: 10.1111/birt.12103

4. Simkin P, Klein MC. Nonpharmacologic approaches to management of labor pain [Internet]. Uptodate.com. 2017 [cited 29 Aug 2018 ]. Available from: https://www.uptodate.com/contents/nonpharmacologic-approaches-to-management-of-labor-pain.

5. Ministério da Saúde (BR). Secretaria de Ciência, Tecnologia e Insumos Estratégicos. Departamento de Gestão e Incorporação de Tecnologias em Saúde. Diretrizes nacionais de assistência ao parto normal: relatório de recomendação. Brasília: Ministério da Saúde, 2017.51 p. 
6. Obstetric Anaesthetists' Association. Analgesia for Labour and C-section. [http://www.oaa-anaes.ac.uk/ui/content/content.aspx?id=194].

7. Ministério da Saúde (BR). Secretaria de Políticos de Saúde. Área Técnica de Saúde da Mulher. Parto, aborto e puerpério: assistência humanizada à mulher. Brasília: Ministério da Saúde, 2001. 199 p.

8. Ministério da Saúde (BR). Secretaria de Atenção à Saúde. Manual prático para implementação da Rede Cegonha. Brasília: 2011.

9. Wagner M. Getting the health out of people's daily lives. Lancet. 1982;8309, p.1207.

10. Amaral H, Sarmento Filho E, Silva D, Barbosa T, Gomes L. Repercussões maternas e fetais da analgesia obstétrica: uma revisão integrativa. Av.Enferm. 2015;33(2):282-294. doi: 10.15446/av.enferm.v33n2.52176

11. Singh KSCS, Yahya N, Misiran K, Masdar A, Nor MN, Yee LC. Combined spinal-epidural analgesia in labour: its effects on delivery outcome. Rev Bras Anestesiol [Internet]. 2016[cited 2018 Aug 29];66(3):259-264. Available from: http://dx.doi.org/10.1016/j.bjane.2014.09.006

12. Reynolds F. Labour analgesia and the baby: good news is no news. Int J Obstet. Anesth. 2011;20(1):38-50. doi: 10.1016/j.ijoa.2010.08.004

13. Felisbino-Mendes MS, Santos LO, Amorim T, Costa IN, Martins EF. O uso de analgesia farmacológica influencia no desfecho de parto?. Acta Paul Enferm [Internet]. 2017[cited 2018 Aug 29];30(5):458-65. Available from: http://dx.doi.org/10.1590/1982-0194201700067

14. Herrera-Gómez A, García-Martínez O, Ramos-Torrecillas J, De Luna-Bertos E, Ruiz C, Ocaña-Peinado FM. Retrospective study of the association between epidural analgesia during labour and complications for the newborn. Midwifery. 2015;31(6):613-6. doi: 10.1016/j.midw.2015.02.013

15. Fernandes RLV, Damasceno AKC, Herculano MMS, Martins RST, Oriá MOB. Pharmacological obstetric analgesia: a study of obstetric and neonatal outcomes. Rev Rene (Fortaleza). 2017;18(5):687-94. doi: 10.1590/1982-0194201700067

16. Ministério da Saúde (BR). Secretaria de Atenção à Saúde. Departamento de Atenção Básica. Atenção ao pré-natal de baixo risco. Brasília: Ministério da Saúde; 2012. 318 p.: il. - (Série A. Normas e Manuais Técnicos) (Cadernos de Atenção Básica, n 32).

17. Saraiva JP, Vogt SE, Rocha JS, Duarte ED, Simão DAS. Association between maternal and neonatal factors and Apgar in usual risk neonates. Rev Rene (Belo Horizonte). 2018;19:1-7. doi: 10.15253/2175-6783.2018193179

18. American Academy of Pediatrics Committee on Fetus and Newborn. American College of Obstetricians and Gynecologists Committee on Obstetric Practice. The Apgar score. Pediatr. 2015;136(4):819-22. doi:10.1542/peds.2015-2651.

19. International Liaison Committee on Resuscitation (ILCOR) Neonatal Task Force. Coordenação Geral do Programa de Reanimação Neonatal da SBP. Programa de Reanimação Neonatal. Reanimação do recém-nascido $\geq 34$ semanas em sal parto: diretrizes 2016 da Sociedade Brasileira de Pediatria. São Paulo: SBP;2016.

20. Greenwell EA, Wyshak G, Ringer SA, Johnson LC, Rivkin MJ, Lieberman E. Intrapartum Temperature Elevation, Epidural Use, and Adverse Outcome in Term Infants. Pediatrics. 2012;129(2):447-454. doi:10.1542/peds.2010-2301

21. Törnell S, Ekéus C, Hultin M, Håkansson S, Thunberg J, Högberg U. Low Apgar score, neonatal encephalopathy and epidural analgesia during labour: a Swedish registry-based study. Acta Anaesthesiol. Scand. 2015;59(4):486-95. doi: 10.1111/aas.12477

22. Riley LE, Celi AC, Onderdonk AB, Roberts DJ, Johnson LC, Tsen LC, et al. Association of Epidural-Related Fever and Noninfectious Inflammation in Term Labor. Obstet. Gynecol. 2011;117(3):588-95. doi: 10.1097/01.aoa.0000414090.52839.ff

23. Hasegawa J, Farina A, Turchi G, Hasegawa Y, Zanello M, Baroncini S. Effects of epidural analgesia on labor length, instrumental delivery, and neonatal short-term outcome. J Anesth. 2013;27:43-47. doi: 10.1007/s00540-012-1480-9

24. Gizzo S, Di Gangi S, Saccardi C, Patrelli TS, Paccagnella G, Sansone L, et al. Epidural Analgesia During Labor: Impact on Delivery Outcome, Neonatal Well-Being, and Early Breastfeeding. Breastfeed Med. 2012;7(4):262-268. doi: 10.1089/bfm.2011.0099

25. Whitburn LY, Jones LE, Davey MA, Small R. The meaning of labour pain: how the social environment and other contextual factors shape women's experiences. BMC Pregnancy Childbirth. 2017, 17(1):157. doi: 10.1186/s12884-017-1343-3

26. Andrade MAC, Lima JBMC. O modelo obstétrico e neonatal que defendemos e com o qual trabalhamos [Internet]. Cadernos Humaniza SUS - Parto e Nascimento. 2014[cited 2018 Aug 29];4:20-46. Available from: http://www.redehumanizasus.net/sites/default/files/caderno_ humanizasus_v4_humanizacao_parto.pdf

27. Gayeski ME, Brüggemann OM. Métodos não farmacológicos para alívio da dor no trabalho de parto: uma revisão sistemática. Texto Contexto Enferm [Internet]. 2010 [cited 2018 Aug 29];19(4):774-782. Available from: http://dx.doi.org/10.1590/S0104-07072010000400022

28. Liu L, Coenen A, Tao H, Jansen KR, Jiang AL. Developing a prenatal nursing care. International Classification for Nursing Practice catalogue. Int Nursing Review. 2017;64:371-8. doi: 10.1111/inr.12325

29. Alleemudder DI, Kuponiyi Y, Kuponiyi C, McGlennan A, Fountain S, Kasivisvanathan R. Analgesia for labour: an evidence-based insight for the obstetrician. Obstetr Gynaecol. 2015;17:147-55. doi: 10.1111/tog.12196

30. Silva TC, Bisognin P, Prates LA, Bortoli CFC, Oliveira, G, Ressel LB. Práticas de atenção ao parto e nascimento: uma revisão integrativa. RECOM. 2017;7:e1294. doi: 10.19175/recom.v7i0.1294 